\title{
Student Praise in the Modern Classroom: The Use of Praise Notes as a Productive Motivational Tool
}

\author{
Matthew R. Hodgman (corresponding author) \\ Dept. of General Education, Goodwin College \\ 1 Riverside Drive, East Hartford, CT, 06118, USA \\ Tel: 1-860-528-4111_E-mail: mhodgman@goodwin.edu
}

Received: August 18, 2014 Accepted: September 2, 2014 Published: September 5, 2014

doi:10.5296/jet.v2i1.6142 URL: http://dx.doi.org/10.5296/jet.v2i1.6142

\begin{abstract}
Student motivation continues to be a vital topic throughout all levels of education. Various approaches to motivating students have been articulated in education circles but educators are still coming to terms with best-fit models to inspire students in classroom settings. One particular often employed form of student motivation, praise, has been a point of contention and scrutiny in the modern classroom. Praise has the potential to be a productive source of student motivation but only when used in certain capacities and with specific outcomes in mind. This article outlines research on the use of praise by instructors in the classroom in the context of student motivation and specifically discusses the use of praise-notes to productively induce student performance and engagement. The merits of praise notes as a motivational tool are discussed and demonstrated through applicative suggestions for classroom practice.
\end{abstract}

Keywords: Student Performance, Student Motivation, Praise, Praise Notes, Student Engagement

\section{Introduction}

Student motivation has continuously been an important topic in education at all levels, especially as student populations become increasingly diverse. Educators and society at large have eagerly sought to better understand the various factors that influence student motivation. Currently, motivation can be understood as a complex construct that is context-sensitive, dynamic, and changeable (Maclellan, 2005). In relation to student motivation, discussions surrounding student praise have become increasingly prominent and varied. As Carol S. Dweck (1999) points out, praise, if used correctly, is a powerful tool that can help students embrace intellectual challenges, understand the value of effort, and better deal with setbacks; 
however, if used improperly, praise can negatively impact students by rendering them passive and dependent on the opinion of others. Clearly, there is a lot at stake surrounding the use of praise in the classroom. Without a basic understanding of how praise can be used wisely, teachers may end unintentionally disadvantaging or harming their students. With this in mind, this paper will investigate and articulate the value in appropriately and effectively using praise in the classroom as a way to motivate students to employ behaviors that will increase student performance and create a more positive and engaging classroom atmosphere.

At all educational levels it is important for instructors to understand the potential value of motivational practices. Student engagement remains an important concern among educators. It is natural for instructors to praise students for good performance and for student attempts to positively contribute to a productive classroom atmosphere. Although attempts at praise are often motivated by a genuine desire to help and encourage students, few instructors have likely investigated the complex nature of praise as it applies to student motivation or considered the ways praise can be potentially harmful to students.

\section{Research on Praise as Motivational Classroom Tool}

Research appears to support the use of praise in classroom environments but only if used in certain capacities. Dweck (1999) explains that when we praise students solely for their intelligence, failure becomes more personal and, ipso facto, more of a disgrace; students consequently become less able to deal with their setbacks. Dweck (1999) found these negative impacts of praising intelligence to be true and equally strong for both high and lower achieving students. Students can be sensitive to comments made about their personal characteristics and thus educators need to always keep students' feelings in mind when attempting to deploy praise. With this said, Dweck (1999) explains that teachers should praise students but in a way that is enthusiastic about students' strategies, not about how their performance reveals an attribute they may view as unchanging and beyond their control. Thus, Dweck is distinguishing between person praise and process praise by prioritizing the latter over the former. Person praise focuses more on the attributes tied to a specific individual where process praise focuses on the work, efforts, and processes endemic to completing a task. In a study of the effects of person praise and process praise on 111 students' motivation, Haimovitz and Henderlong-Corpus (2011) found that process praise enhances intrinsic motivation and perceived competence more than person praise; person praise decreased motivation for students where process praise increased motivation for students. Conroy, Sutherland, Snyder, Al-Hendawi, and Vo (2009) agree that process praise is more advantageous to increasing student performance (e.g. increasing students' correct responses and the amount of work completed by students) and enhancing classroom atmosphere than person praise. Beyond this agreement, the research of Conroy et al. (2009) illuminates the importance of considering students' individual and cultural differences when using praise. For example, students from different socioeconomic backgrounds and ability levels may respond differently to praise and thus these differences must always be considered before praising students. The authors also explain that effective praise should: be teacher initiated, include specific statements about the appropriate behavior children display, immediately follow a desired behavior, consider where a student is in the process of attaining a particular 
skill, be sincere, and avoid comparisons across students (Conroy et al., 2009). Through a case-study examining the effect of praise on math instruction at a middle school, Haydon and Musti-Rao (2011) found that behavior-specific praise (the rewarding of a specific academic or social behavior with a verbal comment) had a positive impact on student participation, classroom atmosphere (specifically a significant reduction in disruptive classroom behavior), and teacher-student interactions especially when used immediately following a desired behavior. The authors also concluded that teachers can benefit from increasing their adeptness in using praise and suggested that praise is underused as an effective instructional strategy (Haydon and Musti-Rao, 2011). Finally, the research of Partin, Robertson, Maggin, Oliver, and Wehby (2010) shows that teacher praise as positive reinforcement for students' appropriate behavior and the provision of high rates of opportunities for students to respond (OTR) correctly to academic questions, tasks, or demands decreases inappropriate student behaviors and increases appropriate behaviors. Further, consistent and appropriate use of teacher praise and increased OTR may serve as an important 1st step to establish predictable and positive classroom contexts (Partin et al., 2010).

Although most research surrounding the use of process praise is inherently supportive of the practice, there has been recent scholarship aimed at examining the value of process praise in relation to person praise and no praise at all. One such study by Skipper and Douglas (2012) showed that those in the process condition did not differ significantly from those in the control (no praise) group. This finding suggests that process praise may not be inherently positive. However, person praise was shown to be particularly detrimental which is consistent with other research findings and students respond to person, process, and no praise in equally positive manners when they are succeeding (Skipper \& Douglas).

Some educators such as Alfie Kohn believe that praise can have particularly detrimental outcomes for children. Kohn (1996) argues that praising a child can be seen as a manipulative act that could create praise junkies, decrease student interest in activities, steal pleasure, and reduce student achievement. For example, if a child is told he or she has done a good job on a particular task, he or she may be subsequently less motivated to continue working hard on that task. Despite pointing out the dangers of praising children, Kohn (1996) acknowledges that all of expressions of delight are not harmful, instead, we need to consider our motives for what we say and the actual effects of doing so.

Despite Kohn's (1996) opposition to praise in the classroom, the key consensus information from the described research above points to the beneficial use of praise in relation to process or student behaviors as opposed to person praise. This means that teachers are more likely to promote increased student performance and an enhanced classroom environment by being sensitive to the various differences between students in relation to praise, knowing when to deploy praise, knowing how to deploy praise, and knowing that process or behavior-specific praise is more likely to produce positive results.

\section{Praise Notes}

Teacher-written praise notes can have a particularly positive impact on student engagement and learning. These notes have been proven to promote a positive environment and reinforce 
the appropriate use of social skills for students in elementary and middle school. For example, Nelson, Young, Young, and Cox (2010) show that the use of teacher-written praise notes in a middle school significantly reduced the number of student discipline referrals at the school; there was a strong negative correlation between the number of praise notes that were distributed and the number of discipline referrals that students received. In addition, Caldarella, Christensen, Young, and Densley (2011) show that teacher-written praise notes significantly decreased tardiness in an elementary school setting.

Teacher-written praise notes are short written statements acknowledging desired student behaviors. They are often used to increase appropriate social behavior and to strengthen teacher-student relationships. Firstly, and before implementing a praise note system at a K-12 school, it is important to train teachers about the use of praise notes and to notify parents that such a system is being considered. Teacher training might be conducted by an administrator or faculty member who has research-informed experience with utilizing praise in classroom settings and should help teachers understand how to get the most out of a praise note program (Wheatley et al., 2009). As for notifying parents, a letter to parents might read: "We have recently begun using praise notes to encourage appropriate social behaviors at school such as respect, punctuality, and responsibility. Please consider reading these notes with your son or daughter when they arrive home from school to celebrate our students' efforts. If you have any questions or concerns, please contact us at your convenience." Letters to this effect help explain this praise practice to parents and help engender a feeling of community in relation to student success. Praise notes may be used for all students in a particular school or class and can be purposely tailored for selected students who have demonstrated a specific need for behavioral redress. When choosing specific students with recurring behavior issues such as tardiness, it is important to confirm that the student demonstrates a clear pattern of tardiness worth addressing with praise notes instead of a tendency to show up late once or twice a year. Also, teachers and administrators should consider whether or not the student is likely to benefit from praise notes as some actions such as tardiness, may be out of a student's control if he or she depends on someone else to get to school in the morning (Caldarella et al., 2011).

Secondly, once praise note participants have been identified and a letter to parents has been distributed, participating teachers need to understand the types of behaviors they will be looking to praise and remain vigilant in monitoring students for these praise-worthy behaviors. For example, some students may be monitored for specific tardiness issues where others may be monitored for not handing in assignments on time. Once a behavior deserving of praise has been identified, teachers must write praise notes and distribute them to the necessary students in relation to the desired student behavior. For example, if a student is being monitored for tardiness issues, a teacher should take notice of instances where that student shows up on time to class or to school in the morning and subsequently present that student with a praise note. This praise note may take many forms. One effective way to construct praise notes is to generate to 3 inch square pieces of paper that include respective lines for the student's name, date, and the teacher's name. In addition, these notes should have a series of check boxes underneath a heading reading something to the effect of: Thanks for showing one of the following: Respect, Responsibility, Punctuality etc. The note might 
even have a positive picture on it such as a smiling sun or a thumbs up logo. The teacher should make sure to leave room on the note to handwrite in a specific message or praise statement to that student as well. For example, a teacher might write: "being a few minutes early to class is a great way of showing respect to everyone in the class, Stacy." To avoid repetition, these statements should change (if even slightly) from note to note. Praise notes may be more general in nature ("for listening attentively today") or more specific ("for coming to $3^{\text {rd }}$ period class on time today") depending on the desired behavior(s) in question. Notes can be given out whenever the student accomplishes the desired behavior for a set period of time that is determined by teachers and administrators. Copies of the praise note should be retained by each individual teacher and the school's office for record-keeping. In order to increase faculty participation in distributing praise notes, it may be necessary to periodically reward teachers with items such as gift certificates or service vouchers donated by local businesses (Wheatley et al., 2009).

Finally, in order for praise notes to be successful, teachers need to monitor the effects of this practice. In line with the research presented above, teachers need to confirm that praise is given in a frequent, contingent, and specific manner to increase effectiveness. Initially, students should be given praise notes whenever they show the desired behavior. Subsequently, if the teacher notices that the desired target behavior has occurred and is occurring consistently, the frequency of the notes can be faded and potentially eliminated (Caldarella et al., 2011). When noticing that students are not continuously demonstrating the desired behavior after receiving initial praise notes, teachers should not give much attention to these students in order to eliminate potentially attention-seeking behaviors (Caldarella et al., 2011). If teachers notice that certain students never seem to receive praise notes, teachers can watch those students carefully for positive behaviors to praise.

Further, teachers will benefit from keeping a journal that monitors praise note activity quantitatively and qualitatively. For example, teachers should record how many praise notes were distributed daily and to whom. Trends, such as when and where certain students tend to evidence desired behaviors, can be observed and used to inform future use of praise notes. Qualitative data such as recording students' responses to receiving praise notes can help gauge the degree to which these notes are individually acknowledged and taken seriously by specific students. Teachers might ask students: "How did you feel when you received that note today?" or "Did that note make you think about the importance of coming to class on time?" Teachers should generally keep track of when desired behaviors are improving so that the praise note process can be appropriately faded out at that time.

Teachers should share the results of their praise note efforts with colleagues and administrators and seek feedback surrounding the effectiveness of implementation. Teachers may be able to share relevant information that helps in better understanding which students may need to improve certain behaviors. In addition, parents should be encouraged to celebrate praise notes with their children and share their opinions on how they think praise notes are working with administrators and teachers. This feedback will further help teachers gauge the effectiveness of their praise note practice. In the case where praise notes are not having any significant impact, teachers and administrators should carefully consider the 
reasons behind the lack of success and work to either create a praise note system that more aptly address student issues or decide that a different approach to student motivation needs to be pursued. As Kohn (1996) points out, alternatives to praise notes may include: giving no praise, using statements that reflect what was seen by the observer (e.g. "you put your shoes on by yourself"), or simply asking questions (e.g. "what is the hardest part of writing?").

\section{Conclusion}

In conclusion, it is evident that praise can be an effective tool to motivate students if used appropriately. Specifically, teacher-written praise notes can be used to motivate younger students to employ behaviors that will increase student performance and create a more positive and engaging classroom atmosphere. When considering the use of praise in classroom environments it is important to contemplate the ways praise might have a positive or potentially harmful impact on students. This means that teachers should aim to use process praise over person praise and consider the discursive needs, interests, and experiences of students before implementing praise oriented strategies. Although the benefits of using praise to motivate students are apparent, there is research showing that teachers do not often use praise in their everyday instruction, and often are not trained how to effectively use praise in class. Further, some research indicates that students receiving process praise do not benefit significantly from students receiving no praise. Teachers need to consider these findings and seek training opportunities before using praise oriented strategies. If students are not responding positively to praise, alternative avenues to acknowledge students need to be explored.

\section{References}

Caldarella, P., Christensen, L., Young, K. R., \& Densley, C. (2011). Decreasing tardiness in elementary school students using teacher-written praise notes. Intervention in School \& Clinic, 47(2), 104-112. http://dx.doi.org/10.1177/1053451211414186

Conroy, M. A., Sutherland, K. S., Snyder, A., Al-Hendawi, M., \& Vo, A. (2009). Creating a positive classroom atmosphere: Teachers' use of effective praise and feedback. Beyond Behavior, 18(2), 18-26.

Dweck, C. S. (1999). Caution - praise can be dangerous. In B. A. Marlowe \& A.S. Canestrari (Eds.), Educational Psychology in Context: Readings for Future Teachers (pp. 207-217). Thousand Oaks: Sage.

Haimovitz, K., \& Henderlong-Corpus, J. (2011). Effects of person versus process praise on student motivation: Stability and change in emerging adulthood. Educational Psychology, 31(5), 595-609. http://dx.doi.org/10.1080/01443410.2011.585950

Haydon, T., \& Musti-Rao, S. (2011). Effective use of behavior-specific praise: A middle school case study. Beyond Behavior, 20(2), 31-39.

Kohn, A. (1996). Five reasons to stop saying "good job!" In B. A. Marlowe \& A.S. Canestrari (Eds.), Educational Psychology in Context: Readings for Future Teachers (pp. 200-205). Thousand Oaks: Sage. 
Maclellan, E. (2005, November). Academic achievement: The role of praise in motivating students. Active Learning in Higher Education, 6(3), 194-206. http://dx.doi.org/10.1177/ 1469787405057750

Nelson, J. A. P., Young, B. J., Young, E. L., \& Cox, G. (2010). Using teacher-written praise notes to promote a positive environment in a middle school. Preventing School Failure, 54(2), 119-125. http://dx.doi.org/10.1080/10459880903217895

Partin, T. C. M., Robertson, R. E., Maggin, D. M., Oliver, R. M., \& Wehby, J. H. (2010). Using teacher praise and opportunities to respond to promote appropriate student behavior. Preventing School Behavior, 54(3), 172-178. http://dx.doi.org/10.1080/10459880903493179

Skipper, Y., \& Douglas, K. (2012, June). Is no praise good praise? Effects of positive feedback on children's and university students' responses to subsequent failures. British Journal of Educational Psychology, 82(2), 327-339. http://dx.doi.org/10.1111/j.2044-8279. 2011.02028.x

Wheatley, R. K., West, R. P., Charlton, C. T., Sanders, R. B., Smith, T. G., \& Taylor, M. J. (2009). Improving behavior through differential reinforcement: A praise note system for elementary school students. Education and Treatment of Children, 32(4), 551-571.

\section{Copyright Disclaimer}

Copyright reserved by the author(s).

This article is an open-access article distributed under the terms and conditions of the Creative Commons Attribution license (http://creativecommons.org/licenses/by/3.0/). 